\title{
The Value of Duodenal Biopsies in the Evaluation of Megaloblastic Anemia
}

\author{
Nasrin Nisha N. ${ }^{1} \quad$ Sakthisankari Shanmugasundaram ${ }^{2, \odot} \quad$ Kartikayan R. K. ${ }^{3}$ \\ 1PSG Institute of Medical Sciences and Research, Peelamedu, \\ Coimbatore, Tamil Nadu, India \\ 2Department of Pathology, PSG Institute of Medical Sciences and \\ Research, Peelamedu, Coimbatore, Tamil Nadu, India \\ ${ }^{3}$ Department of Gastroenterology, PSG Institute of Medical Sciences \\ Address for correspondence: Sakthisankari Shanmugasundaram, \\ MD (Pathology), Department of Pathology, PSG Institute of \\ Medical Sciences and Research, Peelamedu, Coimbatore, Tamil \\ Nadu 641004, India (e-mail: sakthissankari@gmail.com).
} and Research, Peelamedu, Coimbatore, Tamil Nadu, India

J Lab Physicians 2021;13:291-295.

Abstract

Keywords
- megaloblastic anemia
- tropical sprue
- vitamin $B_{12}$
- folate
- pancytopenia
- intraepithelial
lymphocytosis

\section{Introduction}

Megaloblastic anemia is characterized by the distinctive morphological appearance of developing hematopoietic cells in the bone marrow, resulting from nuclear cytoplasmic asynchrony, occurring as a result of defective deoxyribonucleic

published online

July 12,2021
Introduction Megaloblastic anemia is one of the common causes of anemia in India. Duodenal biopsies are routinely performed in the investigation of megaloblastic anemia. The present study was undertaken to analyze the value of duodenal biopsy in megaloblastic anemia and to correlate endoscopic findings with biopsy. As a secondary aim, the study has also analyzed the hematological profile and vitamin $B_{12}$ and folate status of these patients.

Materials and Methods All the cases of megaloblastic anemia with bone marrow studies diagnosed at PSG Institute of Medical Sciences and Research during the two year period from January 2016 to December 2017 were retrieved. Clinical and laboratory findings (serum vitamin $B_{12}$ and folate levels) and endoscopic findings were retrieved from hospital records of the patients. Duodenal biopsies of these patients reported in the histopathology department were retrieved and reviewed. Statistical analysis was done using SPSS software 20.0.

Results There were 93 cases of megaloblastic anemia diagnosed on bone marrow biopsies. Tropical sprue was diagnosed in $49.5 \%$ of cases, followed by intraepithelial lymphocytosis (17.2\%), peptic duodenitis (17.2\%), and no significant pathology in $16 \%$ of cases. Pancytopenia was present in $54.8 \%$ of cases. Isolated vitamin $B_{12}$ deficiency including low levels was present in $48.38 \%$ and folate deficiency was seen in $4.3 \%$ cases; $34.48 \%$ cases had both vitamin $B_{12}$ and folate deficiency.

Conclusion The incidence of tropical sprue in megaloblastic anemia is $49.5 \%$ in the study. Duodenal biopsy is valuable in the work up of megaloblastic anemia, irrespective of the endoscopic changes in identifying the etiology. 
common cause for megaloblastic anemia in Western countries, dietary deficiency and malabsorption are the common causes in India., Duodenal biopsies are routinely performed in patients with megaloblastic anemia to look for any evidence of malabsorption since tropical sprue (TS) is reported to be more prevalent in India. These biopsies are performed irrespective of the macroscopic endoscopic findings. The present study was undertaken to study the value of duodenal biopsy in patients of megaloblastic anemia and correlate the biopsy findings with endoscopy. As a secondary aim, the study also analyzed the hematological profile of patients with megaloblastic anemia.

\section{Materials and Methods}

Approval was obtained from the institutional human ethics committee before the onset of the study. All the cases of megaloblastic anemia with bone marrow studies diagnosed at PSG Institute of Medical Sciences and Research during the period of 2 years from January 2016 to December 2017 were retrieved. Cases with nonmegaloblastic macrocytic anemia, those with other associated neoplastic conditions like myelodysplastic syndrome, and leukemia were excluded from the study. Hematology assays were performed on a LH 780 hematology analyzer (Beckman Coulter, Inc., United States) using volume conductivity and scatter technology. Clinical and laboratory findings (serum vitamin $\mathrm{B}_{12}$ and folate levels) were retrieved from hospital records of the patients. Duodenal biopsies of these patients reported in the histopathology department were retrieved. Endoscopic findings of these cases were retrieved from hospital information system and tabulated. Histopathological examination was performed after standard processing and hematoxylin and eosin staining procedures. All the biopsy slides were reviewed and only those that had well-oriented villi were included. Histomorphological features like villous and crypt architecture, intraepithelial lymphocyte (IEL) count per hundred enterocytes, and 20 villous tip enterocytes in 5 villi were studied. Up to 20 IELs per 100 enterocytes was considered normal; 21 to 30 IELs per 100 enterocytes and more than 30 per 100 enterocytes were graded as borderline and severe increase, respectively. Inflammatory cell component in lamina propria-lymphocytes, plasma cells, neutrophils, eosinophils, and epithelioid histiocytes were also analyzed and the severity was graded as mild, moderate, and severe.

Only those with unequivocal partial or complete villous atrophy, intraepithelial lymphocytosis, and increase in inflammatory cell content were diagnosed as TS. Patients with increase in IELs and no abnormality of villous architecture (Marsh I, lesion) were categorized as intraepithelial lymphocytosis. Data were analyzed using SPSS software for windows, version 20.0, IBM Corporation, NY, United States.

\section{Results}

There were 93 cases of megaloblastic anemia diagnosed on bone marrow biopsies during the study period. There were 68 (73.2\%) males and 25 (26.8\%) females. Age ranged from
16 to 85 years, the median age being 42 years. Out of 93 cases, vitamin $\mathrm{B}_{12}$ assay was done in all whereas folate levels were available in 73 .

According to the World Health Organization(WHO), vitamin $\mathrm{B}_{12}$ status in adults is defined by the serum levels of the micronutrient with the following cutoffs and definitions: greater than $221 \mathrm{pmol} / \mathrm{L}$ (> $163 \mathrm{pg} / \mathrm{mL}$ ) is vitamin " $\mathrm{B}_{12}$ adequacy"; between 148 and $221 \mathrm{pmol} / \mathrm{L}(109-163 \mathrm{pg} / \mathrm{mL})$ is "low $\mathrm{B}_{12}$ "; and lower than $148 \mathrm{pmol} / \mathrm{L}(<109 \mathrm{pg} / \mathrm{mL})$ is " $\mathrm{B}_{12}$ deficiency."

In our series we found 59 (63.4\%) out of 93 patients to be vitamin $B_{12}$ deficient. 18 (19.3\%) had low vitamin $B_{12}$ levels and $16(17.2 \%)$ were categorized as to have adequate $B_{12}$. Out of the 16 patients with adequate $B_{12}$, 4 had folate deficiency. Five cases had vitamin $B_{12}$ levels more than $2,000 \mathrm{pg} / \mathrm{mL}$.

Isolated vitamin $\mathrm{B}_{12}$ deficiency including low levels was present in $45(48.38 \%)$ patients and folate deficiency (4 ng/mL, reference range being 4.6-34.8 ng/mL) was seen in $4(4.3 \%)$ patients; $32(34.48 \%)$ patients had both vitamin $\mathrm{B}_{12}$ and folate deficiency. Twelve (12.9\%) patients had normal serum vitamin $\mathrm{B}_{12}$ and folate levels.

Considering the hematological parameters, mean hemoglobin and mean corpuscular volume (MCV) of the patients were $6.68 \mathrm{~g} / \mathrm{dL}$ and $103.9 \mathrm{fL}$, respectively. MCV was less than $90 \mathrm{fL}$ in five patients (5\%). These five patients had coexisting iron deficiency anemia (-Table $\mathbf{1}$ ).

Fifty-one patients (54.8\%) had pancytopenia at presentation (defined by hemoglobin less than $11 \mathrm{~g} / \mathrm{dL}$, total WBC count less than $4 \times 10^{9} / \mathrm{L}$ and platelet count less than $150 \times$ $\left.10^{9} / \mathrm{L}\right), 48$ of whom had vitamin $B_{12}$ levels $<30 \mathrm{pg} / \mathrm{mL}$. Forty patients had bicytopenia and two had anemia. Peripheral smear and bone marrow morphology are highlighted in -Figs. 1 and 2.

Duodenal biopsies were available for all 93 patients. Out of these, 46 (49.46\%) patients who had villous blunting of any degree (mild, moderate, or severe) and intraepithelial lymphocytosis in a decrescendo pattern (more IELs in the crypts) and nucleomegaly were diagnosed as TS (-Figs. 3 and 4). Five other cases of TS diagnosed previously did not show unequivocal villous blunting and hence were categorized as intraepithelial lymphocytosis. Sixteen (17.2\%) patients had only intraepithelial lymphocytosis, 16 (17.2\%) had peptic duodenitis, and 15 (16.12\%) had no significant pathology (-Fig. 5).

TS was found to be more frequent in the three groups (isolated vitamin $B_{12}$ deficiency, isolated folate deficiency, and combined $\mathrm{B}_{12}$ and folate deficiency). TS was less frequent in the patients who had normal vitamin $\mathrm{B}_{12}$ and folate levels (-Table 2).

Table 1 Hematological profile of patients with megaloblastic anemia

\begin{tabular}{|l|l|l|}
\hline Hematological parameters & Mean & Range \\
\hline Hemoglobin $(\mathrm{g} / \mathrm{dL})$ & $6.2+2.37$ & $3.0-11.9$ \\
\hline Mean corpuscular volume $(\mathrm{fL})$ & $103.9+15.49$ & $51.8-144.4$ \\
\hline Red cell distribution width $(\%)$ & 19.2 & $16-28$ \\
\hline Platelets $\left(\times 10^{9} / \mathrm{L}\right)$ & 83.8 & $9-315$ \\
\hline Total leucocyte count $\left(\times 10^{9} / \mathrm{L}\right)$ & 3.1 & $1-18.1$ \\
\hline
\end{tabular}




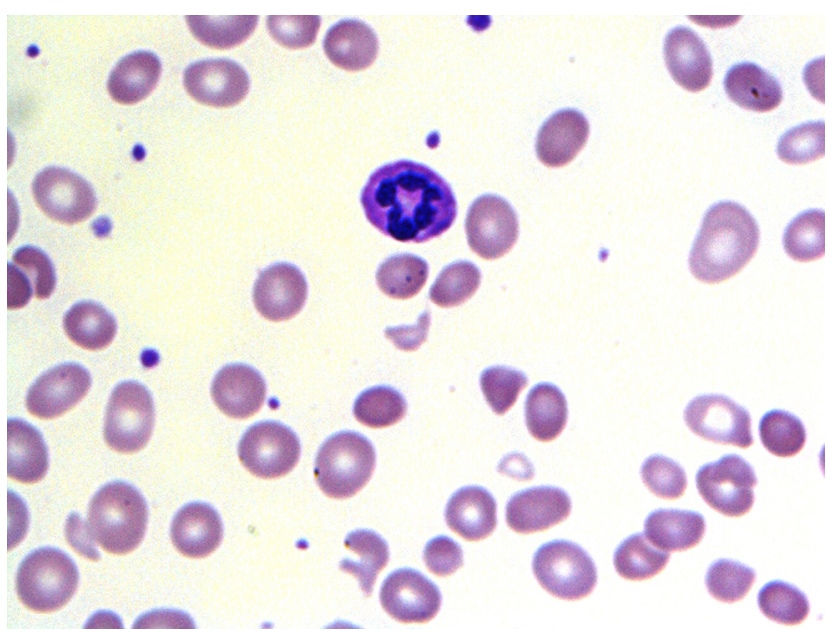

Fig. 1 Peripheral smear with hypersegmented neutrophil and macro-ovalocyte (100×).

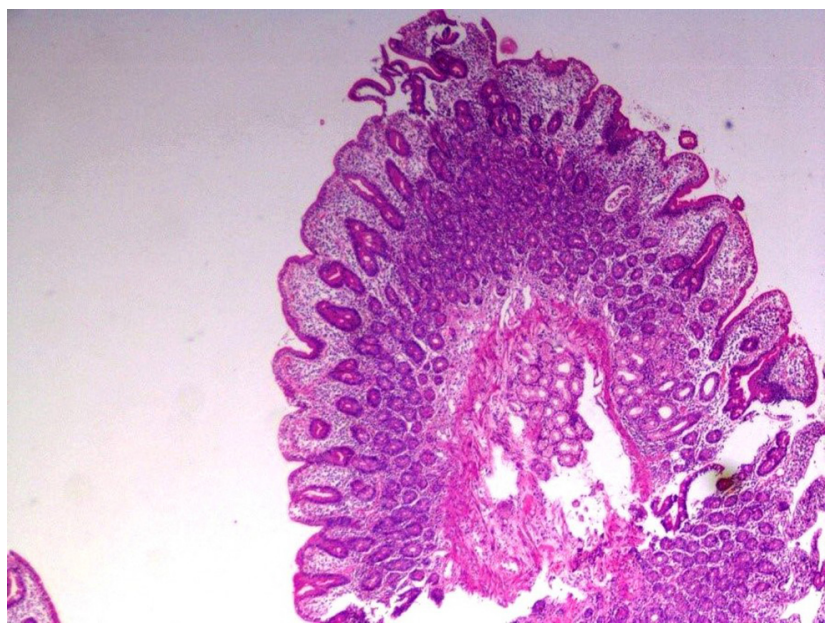

Fig. 3 Duodenal biopsy with villous blunting (4×, Hematoxylin and Eosin).

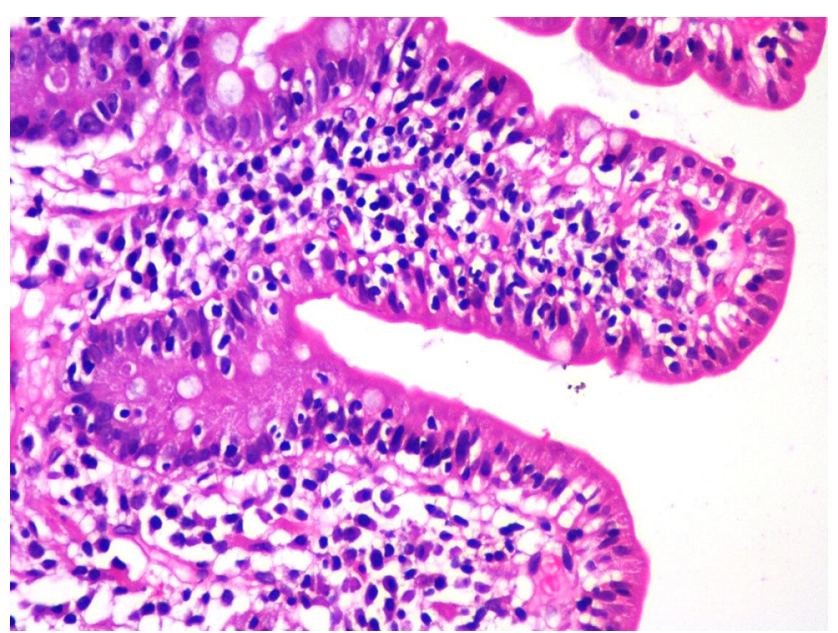

Fig. 5 Duodenal biopsy with marked intraepithelial lymphocytosis (Hematoxylin and Eosin, 40×).

Endoscopic macroscopic changes pertaining to malabsorption like scalloped duodenal and attenuated duodenal folds

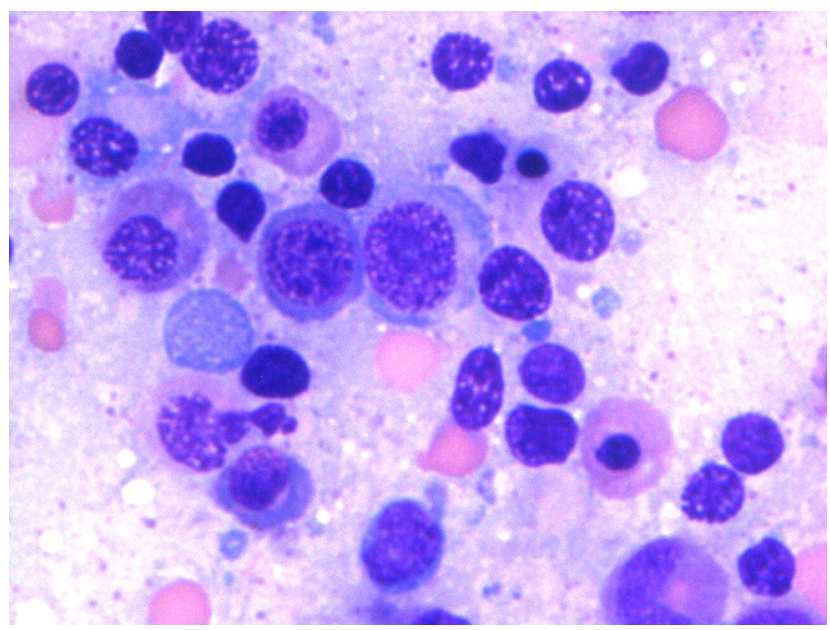

Fig. 2 Bone marrow aspirate showing megaloblastic erythroid hyperplasia (100x).

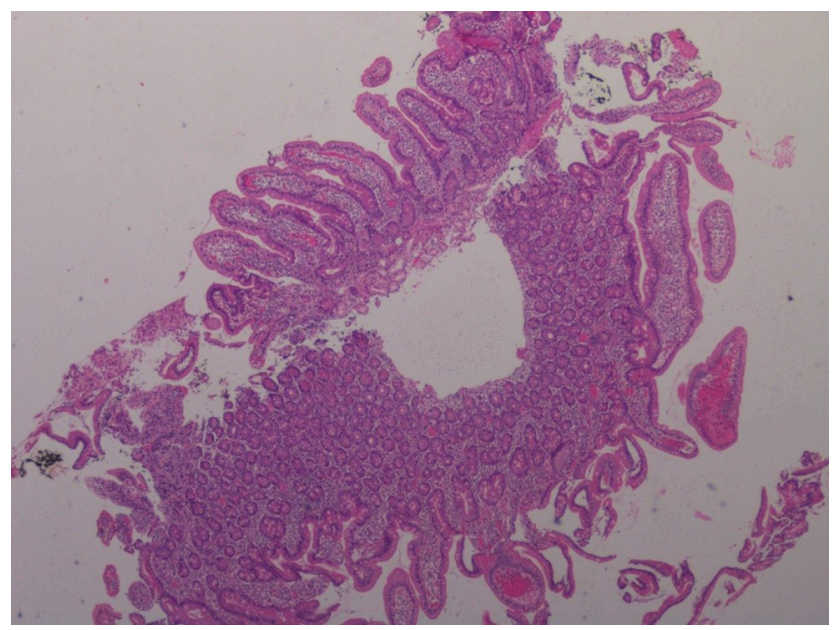

Fig. 4 Duodenal biopsy with variable villous blunting (Hematoxylin and Eosin, $4 \times$ ).

were identified in $26.8 \%(n=25)$ of patients. Of these, the biopsy diagnosis of TS was made in 15 patients (60\%). The remaining cases of TS diagnosed on biopsy showed either normal endoscopic appearance or other features like nodularity ( - Table 3 ).

\section{Discussion}

Megaloblastic anemia is one of the commonest causes for pancytopenia in India. It has a characteristic peripheral smear picture (macrocytosis, ovalocytes, and hypersegmented neutrophils) and low reticulocyte count. ${ }^{2}$ Bone marrow examination is done to rule out other neoplastic disorders which can have megaloblastosis, like myelodysplastic syndrome and leukemia. Serum vitamin $B_{12}$ and folate levels will point toward the cause for megaloblastic anemia. ${ }^{6.7}$ Duodenal biopsies are performed to identify if there is any evidence of malabsorption. The study reports a male predominance with a ratio of 2.7:1 which is considerably higher when compared with a vast majority of other studies. ${ }^{8,9}$ The possible explanation could be the higher population of elderly men in the 
Table 2 Duodenal biopsy findings in patients with vitamin $B_{12}$ and folate deficiency

\begin{tabular}{|l|l|l|l|l|}
\hline $\begin{array}{l}\text { Number of cases } \\
(N=93)\end{array}$ & Tropical sprue & $\begin{array}{l}\text { Intraepithelial } \\
\text { lymphocytosis }\end{array}$ & Peptic duodenitis & No significant pathology \\
\hline $\begin{array}{l}\text { Vitamin } B_{12} \text { deficiency } \\
n=45\end{array}$ & $24(53.3 \%)$ & $8(17.7 \%)$ & $5(11.1 \%)$ & $8(17.7 \%)$ \\
\hline $\begin{array}{l}\text { Folate deficiency } \\
n=4\end{array}$ & $3(75 \%)$ & - & $1(25 \%)$ & - \\
\hline $\begin{array}{l}\text { Both } \\
n=32\end{array}$ & $17(53.1 \%)$ & $6(18.75 \%)$ & $6(18.75 \%)$ & $4(12.5 \%)$ \\
\hline $\begin{array}{l}\text { Normal } \\
n=12\end{array}$ & $2(16.6 \%)$ & $2(16.6 \%)$ & $4(33.36 \%)$ & $3(25 \%)$ \\
\hline
\end{tabular}

Table 3 Endoscopic findings with histological diagnosis

\begin{tabular}{|l|l|l|l|l|}
\hline $\mathbf{N}=\mathbf{9 3}$ & $\begin{array}{l}\text { Tropical sprue } \\
(n=46)\end{array}$ & $\begin{array}{l}\text { Intraepithelial } \\
\text { lymphocytosis }(n=16)\end{array}$ & $\begin{array}{l}\text { Peptic duodenitis } \\
(n=16)\end{array}$ & $\begin{array}{l}\text { No significant } \\
\text { pathology } \\
(n=15)\end{array}$ \\
\hline $\begin{array}{l}\text { Scalloped duodenal folds } \\
n=25\end{array}$ & $15(60 \%)$ & $2(8 \%)$ & $3(12 \%)$ & $5(20 \%)$ \\
\hline $\begin{array}{l}\text { Nodularity } \\
n=25\end{array}$ & $10(40 \%)$ & $6(24 \%)$ & $3(12 \%)$ & $6(24 \%)$ \\
\hline $\begin{array}{l}\text { Gastroduodenitis } \\
n=12\end{array}$ & $6(50 \%)$ & $2(16.6 \%)$ & $8(2.33 \%)$ & $3(25 \%)$ \\
\hline $\begin{array}{l}\text { No macroscopic } \\
\text { abnormality } \\
n=31\end{array}$ & $15(48.5 \%)$ & $6(19.3 \%)$ & & $2(6.45 \%)$ \\
\hline
\end{tabular}

series in whom vitamin $B_{12}$ deficiency due to intestinal malabsorption are reported to be common. ${ }^{10}$

Cobalamin and folate deficiency are predominantly due to decreased dietary intake or malabsorption in Indian population while pernicious anemia has been reported to be the common etiology in Western population. ${ }^{11,12}$ Vitamin $B_{12}$ deficiency has been reported to be the common cause for megaloblastic anemia in our population constituting to $63 \%$, similar to that of Khandhuri et al $(68 \%)^{8}$ and Sarode et al (76\%). ${ }^{9}$ Combined vitamin $\mathrm{B}_{12}$ and folate deficiency was seen in $34 \%$ of cases which is slightly higher when compared with $8.8 \%$ and $12 \%$ reported by Sarode et al and Khandhuri et al, respectively. This is probably because of higher percentage of people with malabsorption in this series where combined micronutrient deficiencies are common. Folate deficiency was seen in $4.3 \%$ of patients which is similar to other studies. The cases with vitamin $B_{12}$ levels greater than $2,000 \mathrm{pg} / \mathrm{mL}$ could represent cases treated inadvertently with vitamin $\mathrm{B}_{12}$ injections prior to investigation.

Pancytopenia and bicytopenia were observed in 54.8\% and $43 \%$ of the patients, respectively. There are wide variations reported for the frequency of pancytopenia ranging from 17.2 to $43.8 \%{ }^{13,14}$ Another study done in South India has reported pancytopenia in $40 \%$ of the patients. ${ }^{15}$ The higher incidence of pancytopenia in our population can be attributed to severe vitamin $B_{12}$ deficiency in these patients ( 48 out of 51 had vitamin $B_{12}$ levels $<30 \mathrm{pg} / \mathrm{mL}$ ). Mean MCV observed in the current study was $103.9+15.49 \mathrm{fL}$, which is lower when compared with that reported by Chidambaram et al ( $110 \mathrm{fL}) .{ }^{15} \mathrm{MCV}$ was found to be normal in $5.3 \%$ of the patients which is lower than another study. ${ }^{14}$
TS was the commonest biopsy diagnosis in the study accounting for $49.5 \%$ of patients diagnosed as having megaloblastic anemia, which is similar to most other studies. ${ }^{16,17}$ Endoscopic finding of scalloped duodenal folds was identified in $32.6 \%$ of TS. In the remaining cases, the diagnosis was possible only with the help of biopsy.

The diagnostic yield of gastrointestinal endoscopy is low in our study. This could be because subtle endoscopic changes were not documented since duodenal biopsies were routinely done in all the patients with megaloblastic anemia. However, Sharma et al ${ }^{18}$ in their systematic review had found normal duodenal folds to be more common in TS.

Intraepithelial lymphocytosis without villous abnormality was the second commonest biopsy finding identified in $34.7 \%$ of patients. IEL without villous abnormality had been reported in various conditions such as gluten-sensitive enteropathy, infections, autoimmune conditions, drugs, and idiopathic etiology.$^{19}$ It has also been reported to be an early morphological feature of sprue. ${ }^{19,20}$

TS and IEL without villous abnormality together constituted $66.6 \%$ of cases, indicating malabsorption as the etiology for vitamin $B_{12}$ and folate deficiency in these cases. Hence, biopsy contributes in identifying the etiology in 66.6\% of cases.

In the remaining cases, the etiology of megaloblastic anemia could have been dietary deficiency or intrinsic factor deficiency.

Although the guidelines for investigation of megaloblastic anemia recommends serological assays of anti-intrinsic factor antibodies (anti-IFAB) ${ }^{5}$ the incidence of pernicious anemia is very low in India. Duodenal biopsies have become a 
routine practice in the workup more based on the evidence of high number of cases of TS being reported. Anti-IFAB levels were not done in the patients in the study.

It was found in the present study that routine duodenal biopsy in cases of megaloblastic anemia yields etiologic information in majority of the cases, irrespective of endoscopy. Hence it is recommended even in the absence of macroscopic endoscopic changes.

Current spectrum of malabsorption in India has found celiac sprue to be increasing in incidence. ${ }^{19}$ Since the clinical, endoscopic, and histologic difference between celiac and tropical sprue are not well defined, serum antibodies against tissue transglutaminase and endomysial antibodies are needed in cases where there is no response to therapy for TS.

\section{Limitations}

Since this is a retrospective study, follow-up of patients to look for response to therapy for TS is not available. Since the study was conducted in a teaching hospital, endoscopy being done by different endoscopists would have influenced the results. Serological tests for celiac sprue and anti-IFAB antibodies were not done in the study.

\section{Conclusion}

Pancytopenia was the commonest presentation of megaloblastic anemia; vitamin $\mathrm{B}_{12}$ deficiency and folate deficiency constituted $82 \%$ and $4.3 \%$, respectively. The incidence of TS in megaloblastic anemia is as high as $49.5 \%$ in the study population. Duodenal biopsy is valuable in the workup of megaloblastic anemia, irrespective of the endoscopic changes in identifying the etiology.

\section{Authors' Contribution}

N.N.N. and S.S. contributed to the literature research, data acquisition, and manuscript preparation. All the authors contributed to the development of the concept, design, definition of intellectual content, and manuscript editing and review. S.S. is the guarantor for this article.

\section{Ethical Approval}

Ethical approval was obtained from the institutional human ethics committee.

\section{Conflicts of Interest}

None declared.

\section{References}

1 Hoffbrand V, Provan D. ABC of clinical haematology. Macrocytic anaemias. BMJ 1997;314(7078):430-433
2 Hoffbrand V, Moss PAH, Pettit JE, Megaloblastic anaemias. In: Essential Haematology. 5th ed. Massachussetts: Wiley-Blackwell; 2006 44-57

3 Desai HG, Antia FP. Vitamin B 12 malabsorption due to intrinsic factor deficiency in Indian subjects. Blood 1972;40(5):747-753

4 Allen LH. Causes of vitamin B12 and folate deficiency. Food Nutr Bull 2008;29(2(Suppl):S20-S34, discussion S35-S37

5 Devalia V, Hamilton MS, Molloy AM; British Committee for Standards in Haematology. Guidelines for the diagnosis and treatment of cobalamin and folate disorders. $\mathrm{Br}$ J Haematol 2014;166(4):496-513

6 Khanduri U, Sharma A. Megaloblastic anaemia: prevalence and causative factors. Natl Med J India 2007;20(4):172-175

7 Unnikrishnan V, Dutta TK, Badhe BA, Bobby Z, Panigrahi AK. Clinico-aetiologic profile of macrocytic anemias with special reference to megaloblastic anemia. Indian J Hematol Blood Transfus 2008;24(4):155-165

8 Sarode R, Garewal G, Marwaha N, et al. Pancytopenia in nutritional megaloblastic anaemia. A study from Northwest India. Trop Geogr Med 1989;41(4):331-336

9 Khanduri U, Sharma A, Joshi A. Occult cobalamin and folate deficiency in Indians. Natl Med J India 2005;18(4):182-183

10 Holt PR. Intestinal malabsorption in the elderly. Dig Dis 2007;25(2):144-150

11 Singla R, Garg A, Surana V, Aggarwal S, Gupta G, Singla S. Vitamin B12 deficiency is endemic in Indian population: a perspective from North India. Indian J Endocrinol Metab 2019;23(2):211-214

12 Ghoshal UC, Mehrotra M, Kumar S, et al. Spectrum of malabsorption syndrome among adults and factors differentiating celiac disease \& tropical malabsorption. Indian J Med Res 2012;136(3):451-459

13 Kumar R, Kalra SP, Kumar H, Anand AC, Madan H. Pancytopenia-a six year study. J Assoc Physicians India 2001;49:1078-1081

14 Sekhar J, Stabler SP. Life-threatening megaloblastic pancytopenia with normal mean cell volume: case series. Eur J Intern Med 2007;18(7):548-550

15 Chidambaram Y, Mambatta AK, Sivara SK. Tropical sprue in megaloblastic anemia. Int J Res Med Sci 2017;5:4133-4137

16 Dutta AK, Balekuduru A, Chacko A. Spectrum of malabsorption in India-tropical sprue is still the leader. J Assoc Physicians India 2011;59:420-422

17 Balasubramanian P, Badhe BA, Ganesh RN, Panicker LC, Mohan P. Morphologic spectrum of duodenal biopsies in malabsorption: a study from Southern India. J Clin Diagn Res 2017;11(7):EC17-EC21

18 Sharma P, Baloda V, Gahlot GP, et al. Clinical, endoscopic, and histological differentiation between celiac disease and tropical sprue: a systematic review. J Gastroenterol Hepatol 2019;34(1):74-83

19 Hammer ST, Greenson JK. The clinical significance of duodenal lymphocytosis with normal villus architecture. Arch Pathol Lab Med 2013;137(9):1216-1219

20 Lauwers GY, Fasano A, Brown IS. Duodenal lymphocytosis with no or minimal enteropathy: much ado about nothing? Mod Pathol 2015;28(Suppl 1) :S22-S29 